\title{
Hard X-ray photoelectron and X-ray absorption spectroscopy characterization of oxidized surfaces of iron sulfides
}

\author{
Yuri Mikhlin ${ }^{\mathrm{a}, *}$, Yevgeny Tomashevich ${ }^{\mathrm{a}}$, Sergey Vorobyev $^{\mathrm{a}, \mathrm{b}}$, Svetlana Saikova $^{\mathrm{b}}$, \\ Alexander Romanchenko ${ }^{a}$, Roberto Félix ${ }^{c}$ \\ a Institute of Chemistry and Chemical Technology of the Siberian Branch of the Russian Academy of sciences, Akademgorodok, 50/24, Krasnoyarsk, 660036, \\ Russia \\ b Siberian Federal University, Svobodny pr. 79, Krasnoyarsk, 660041, Russia \\ ${ }^{\mathrm{c}}$ Renewable Energy, Helmholtz-Zentrum Berlin für Materialien und Energie GmbH, Lise-Meitner-Campus, Hahn-Meitner-Platz 1, 14109 Berlin, Germany
}

\section{A R T I C L E I N F O}

\section{Article history:}

Received 17 May 2016

Received in revised form 23 June 2016

Accepted 29 June 2016

Available online 1 July 2016

\section{Keywords:}

HAXPES

XANES

Pyrite

Pyrrhotite

Oxidation

Undersurface

\begin{abstract}
A B S T R A C T
Hard X-ray photoelectron spectroscopy (HAXPES) using an excitation energy range of $2 \mathrm{keV}$ to $6 \mathrm{keV}$ in combination with Fe K- and S K-edge XANES, measured simultaneously in total electron (TEY) and partial fluorescence yield (PFY) modes, have been applied to study near-surface regions of natural polycrystalline pyrite $\mathrm{FeS}_{2}$ and pyrrhotite $\mathrm{Fe}_{1-\mathrm{x}} \mathrm{S}$ before and after etching treatments in an acidic ferric chloride solution. It was found that the following near-surface regions are formed owing to the preferential release of iron from oxidized metal sulfide lattices: (i) a thin, no more than $1-4 \mathrm{~nm}$ in depth, outer layer containing polysulfide species, (ii) a layer exhibiting less pronounced stoichiometry deviations and low, if any, concentrations of polysulfide, the composition and dimensions of which vary for pyrite and pyrrhotite and depend on the chemical treatment, and (iii) an extended almost stoichiometric underlayer yielding modified TEY XANES spectra, probably, due to a higher content of defects. We suggest that the extended layered structure should heavily affect the near-surface electronic properties, and processes involving the surface and interfacial charge transfer.
\end{abstract}

(C) 2016 Elsevier B.V. All rights reserved.

\section{Introduction}

Pyrite and pyrrhotite are the most common sulfide minerals of iron. These minerals are frequently found together with non-ferrous base metals and precious metals in ores and play an important role in the biogeochemical sulfur cycle and other environmental processes [1-4]. Pyrite $\left(\mathrm{FeS}_{2}\right)$ has a cubic crystal lattice composed of low-spin ferrous iron and disulfide $\mathrm{S}_{2}{ }^{2-}$ groups with a bulk band gap of about $0.95 \mathrm{eV}$ [5-7]; it is one of the promising materials for photovoltaic [8,9], battery cathode $[10,11]$, thermoelectric [12] and other applications. Pyrrhotites $\left(\mathrm{Fe}_{1-\mathrm{x}} \mathrm{S}\right.$, $0<\mathrm{x}<0.2$ ) crystallize in a NiAs-like structure consisting of highspin $\mathrm{Fe}^{2+}$, monosulfide anions and a system of ordered cationic vacancies, having a very narrow gap of about $0.05 \mathrm{eV}[1,13,14]$. The chemical reactivity of iron sulfides in the environment and during mineral processing, as well as their electronic and optical properties strongly depend on the composition and structure of the real surfaces formed in natural and technological environ-

\footnotetext{
* Corresponding author.

E-mail address: yumikh@icct.ru (Y. Mikhlin).
}

ments. It is known from X-ray photoelectron spectroscopy (XPS) and other surface-sensitive techniques [2-4,15-34] that iron can be easily released from the lattice of these compounds, leaving non-equilibrium metal-deficient surface layers. The resulting surface sulfur enrichment is generally modest for oxidation-resistant pyrite, with intrinsic (fractured) pyrite surfaces possibly even being S-deficient [2-6,17-26]. In contrast, the metal depleted layer incorporates di- and polysulfide species and low-spin Fe(II) and can be as thick as several micrometers at pyrrhotite reacted in acidic solutions under certain conditions [27-35]; for example, Pratt and co-workers [30-32] have reported Auger depth profiles of several reacted pyrrhotites. It remains, however, unclear how the undersurface species alter with depth, in particular, because $\mathrm{Ar}^{+}$ ion sputtering employed in many works could seriously affect the chemical state of Fe and S.

The characterization effectiveness of conventional XPS, which has been widely used to study intrinsic and reacted (oxidized) surfaces of pyrite and pyrrhotite, is limited to photoelectron kinetic energies lower than $1.5 \mathrm{keV}$, corresponding to inelastic mean free path (IMFP) and information depths (ID $=3 \times$ IMFP) in the order of a few nanometers [37]. Hard X-ray photoelectron spectroscopy (HAXPES) operates in the energy range of photons and emitted elec- 
trons of up to $10-15 \mathrm{keV}$ with the IMFP approaching several tens of nanometers [36-40]. HAXPES is a non-destructive technique that allows to determine chemical shifts of core levels and chemical states of the atoms of interest at varying depths. As far as we know, this technique has not yet been applied to reacted iron sulfides, although several studies on related materials, in particular, copperdepleted and copper-rich $\mathrm{Cu}(\mathrm{In}, \mathrm{Ga}) \mathrm{Se}_{2}$ samples [41,42] have been reported.

In the present work, HAXPES was used in combination with X-ray absorption near-edge structure spectroscopy (XANES) measured both in partial fluorescence yield (PFY) and near-surfacesensitive total electron yield (TEY) modes, to probe the unoccupied density of states and the chemical states of the probed elements. A number of XANES studies on iron sulfides have been reported previously [33,43-56], but the difference between TEY and PFY Kedge spectra of air-oxidized and chemically etched materials has not been analyzed yet. Here, samples of each mineral (i.e., pyrite and pyrrhotite) polished in air were compared with those treated with an acidic ferric chloride solution to probe the effect of exposure to the leaching (etching) medium in hydrometallurgy and natural environments, and in materials science. The study revealed "layered" structures of the reacted undersurface both at pyrrhotite and pyrite, even if only oxidized in an ambient air, which are expected to exhibit altered electronic and chemical properties.

\section{Experimental}

Natural pyrite crystals (Ozernoye ore deposit, Russia) without visible inclusions of foreign phases had an average composition of $\mathrm{FeS}_{2.0}$ and contained the following impurities (in wt.\%, as determined by X-ray fluorescence analysis): $\mathrm{Cu} 0.14$, Si 1.03 , Zn 0.11 , Ca 0.19 . Natural polycrystalline hexagonal pyrrhotite $\mathrm{Fe}_{9} \mathrm{~S}_{10}$ from a Norilsk ore deposit contained about 2 wt.\% impurity of pentlandite, $(\mathrm{Fe}, \mathrm{Ni})_{9} \mathrm{~S}_{8}$, as described in detail elsewhere [33-36]. Plates of approximately $2 \times 5 \times 6 \mathrm{~mm}$ were cut from the massive minerals, abraded on silicon carbide paper, and then cleaned by wet filter paper to remove fine particles. For oxidative etching, the plates were conditioned in $0.5 \mathrm{M} \mathrm{FeCl}_{3}+0.5 \mathrm{M} \mathrm{HCl}$ solutions at $50^{\circ} \mathrm{C}$ for $30 \mathrm{~min}$, rinsed with distilled water and introduced in vacuum.

HAXPES and XANES measurements were carried out at the High Kinetic Energy Photoelectron Spectrometer (HIKE) endstation located at the BESSY KMC- 1 beamline at Helmholtz-Zentrum Berlin (HZB). The endstation was operated with a background pressure in the order of $10^{-9} \mathrm{mBar}$. A Si(l 111 1) double-crystal pair was used to monochromatize the energy of the (horizontally-polarized) Xray beam. The beam intensity was constant, as monitored by a $\mathrm{N}_{2}$ ionization chamber, in the top-up mode of the storage ring. The monochromator resolution and the flux at the sample varied with photon energy; further details about the experimental setup can be found in refs. $[39,40]$. Photoemission spectra were collected using a Scienta R4000 hemispherical analyzer modified for high transmission and high resolution at electron kinetic energies up to $10 \mathrm{keV}$. The analyzer is positioned at about $90^{\circ}$ to the incident beam, and the HAXPES spectra were collected using grazing incidence of the photon beam and normal emission of electrons from the sample surface. The survey and the detail HAXPES spectra were recorded at pass energies of $500 \mathrm{eV}$ and $200 \mathrm{eV}$, respectively. The spectra were acquired at photon energies from $2 \mathrm{keV}$ to $6 \mathrm{keV}$ and, in some cases, to $9 \mathrm{keV}$; the slit width was of $0.5 \mathrm{~mm}$ for all the excitation photon energies. Atomic ratios of elements $\left(I_{i, h v}\right)$ relative to $S$ were calculated from the intensity area of the detail spectra for each energy $\left(A_{i, h v}\right)$ employing photoionization cross-sections $\left(\sigma_{i, h v}\right)$ tabulated in $[57,58]$ and the ones extrapolated for the higher energies, and taking into account IMFP $\left(\lambda(K E)_{i}\right)$ calculated for $\mathrm{FeS}_{2}$ and $\mathrm{Fe}_{9} \mathrm{~S}_{10}$ employing TPP-2M formula [38] and analyzer's transmission function $\left(T(K E)_{i}\right)$ [40-42] using following equation

$I_{i, h v}=A_{i, h v} \cdot \sigma_{S, h v} \cdot \lambda(K E)_{S} \cdot T(K E)_{S} /\left[\mathrm{A}_{\mathrm{S} 2 \mathrm{p}, \mathrm{h} v} \cdot \sigma_{i, h v} \cdot \lambda(K E)_{i} \cdot T(K E)_{i}\right]$.

To calibrate the energy scale, the $\mathrm{Au} 4 \mathrm{f}_{7 / 2}$ line of a clean gold foil was measured and set to $84.0 \mathrm{eV}$. When necessary, the binding energies were corrected for electrostatic charging using the $\mathrm{C} 1 \mathrm{~s}$ peak $(285.0 \mathrm{eV})$ from aliphatic carbon contamination. The spectra were fitted after subtraction of a Shirley background with GaussianLorenzian peak shapes using CasaXPS program package (version 2.3.16 PR 1.6). The atomic ratio and $S 2 p$ fitting uncertainties were estimated to be within 5-10\%.

$\mathrm{X}$-ray absorption spectra were acquired simultaneously in total electron yield (TEY) and partial fluorescence yield (PFY) modes, by using a photon beam incidence angle of $45^{\circ}$. The leakage current was measured with a Keithley picoammeter; fluorescence photons were detected using a Bruker XFlash ${ }^{\circledR} 4010$ fluorescence detector in the $\mathrm{S} K \alpha$ or Fe K $\alpha$ photon energy windows for S K-edge and Fe K-edge, correspondingly. An energy step of $0.2 \mathrm{eV}$ was employed for these measurements.

\section{Results}

\subsection{HAXPES}

\subsubsection{Pyrite}

Fig. 1 shows the HAXPES detail spectra of the Fe 2p, O 1s, S 2p and valence band (VB) energy regions of pyrite samples abraded in air (upper panels) or etched in $0.5 \mathrm{M}$ ferric chloride solution (bottom panels), as measured using various excitation photon energies. The spectra are normalized to the maximum intensity value for comparison of peak shape. Peak broadening in spectra measured with higher excitation energies is ascribed to increased $\mathrm{X}$-ray line widths monochromatized with the $\mathrm{Si}\left(\begin{array}{lll}1 & 1 & 1\end{array}\right)$ crystal. This effect can be especially seen in the spectra measured with $6 \mathrm{keV}$ excitation energy [39]. The Fe 2p spectra show a narrow peak at $707.2 \mathrm{eV}$ which is recognized as a $\mathrm{Fe} 2 \mathrm{p}_{3 / 2}$ signal from low-spin $\mathrm{Fe}(\mathrm{II})$ in the pyrite lattice. A second $\mathrm{Fe} 2 \mathrm{p}_{3 / 2}$ contribution found at a higher binding energy (BE) is mainly due to a multiplet structure (four maxima plus satellite) with a highest intensity at $\sim 709.8 \mathrm{eV}$ from surface Fe(III) oxyhydroxides [17-22]. The presence of this Fe $2 p$ feature is in agreement with the $\mathrm{O} 1 \mathrm{~s}$ spectra containing an $\mathrm{O}^{2-}$ contribution $(530.4 \mathrm{eV})$, which reduces in spectra taken with increasing excitation energy and, therefore, probing depth. Minor contributions from Fe(III)-S and high-spin $\mathrm{Fe}(\mathrm{II})-\mathrm{S}$ species [22] may be roughly fitted by one maximum at about $708.8 \mathrm{eV}$. Additional oxygen species that can be identified in the $01 \mathrm{~s}$ spectra derive from water adsorbed to pyrite $(533.5 \mathrm{eV})$, ferric hydroxides $(535.5 \mathrm{eV}$, not in electronic equilibrium with pyrite), and oxygen in carbonaceous contamination and OH groups $(\sim 532 \mathrm{eV})$.

The $S 2 \mathrm{p}$ spectra are dominated by the doublet with the $S 2 \mathrm{p}_{3 / 2}$ peak at $162.6 \mathrm{eV}$, which is due to $\mathrm{S}_{2}{ }^{2-}$ anions in pyrite. Additional minor lines are ascribed to monosulfide $(161.8 \mathrm{eV})$, and polysulfide (163.5 eV) and satellite at about $164.5 \mathrm{eV}$ [17-24] and slightly vary with the excitation photon energy. The VB spectra are dominated by non-bonding Fe $3 \mathrm{~d}^{6}$ orbital states in the vicinity of $2 \mathrm{eV}$ below the Fermi level [5-7]. The relative intensity of this peak decreases with increasing the excitation energy owing to lower Fe 3d photoionization cross-section values [57]. The spectra from the chemically etched pyrite (lower panels) are quite similar to the abraded samples. The main differences are found in the $01 \mathrm{~s}$ spectra, where the contributions of $\mathrm{O}^{2-}$ species are not detected and contributions of adsorbed water are substantially reduced. These changes in oxygen content suggest a removal of surface Fe(III) oxide species and the formation of a more hydrophobic surface. The intensity of polysul- 


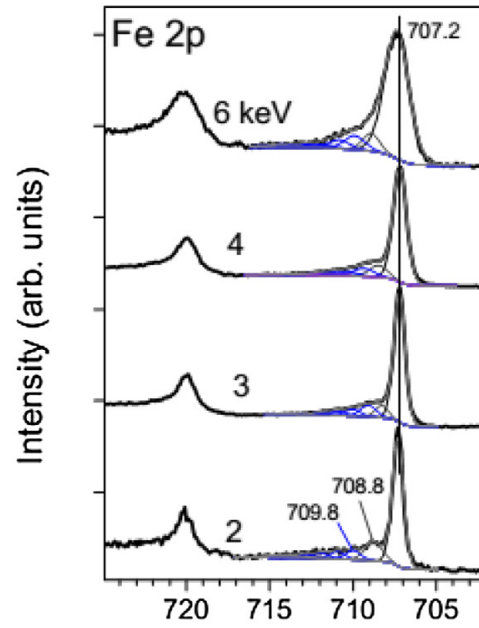

Binding energy $(\mathrm{eV})$

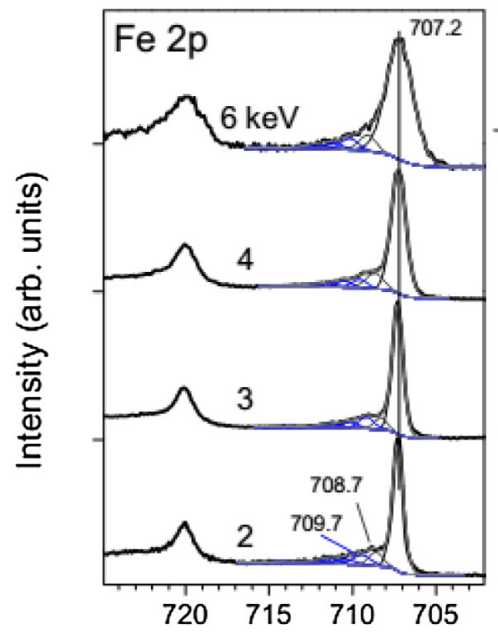

Binding energy $(\mathrm{eV})$
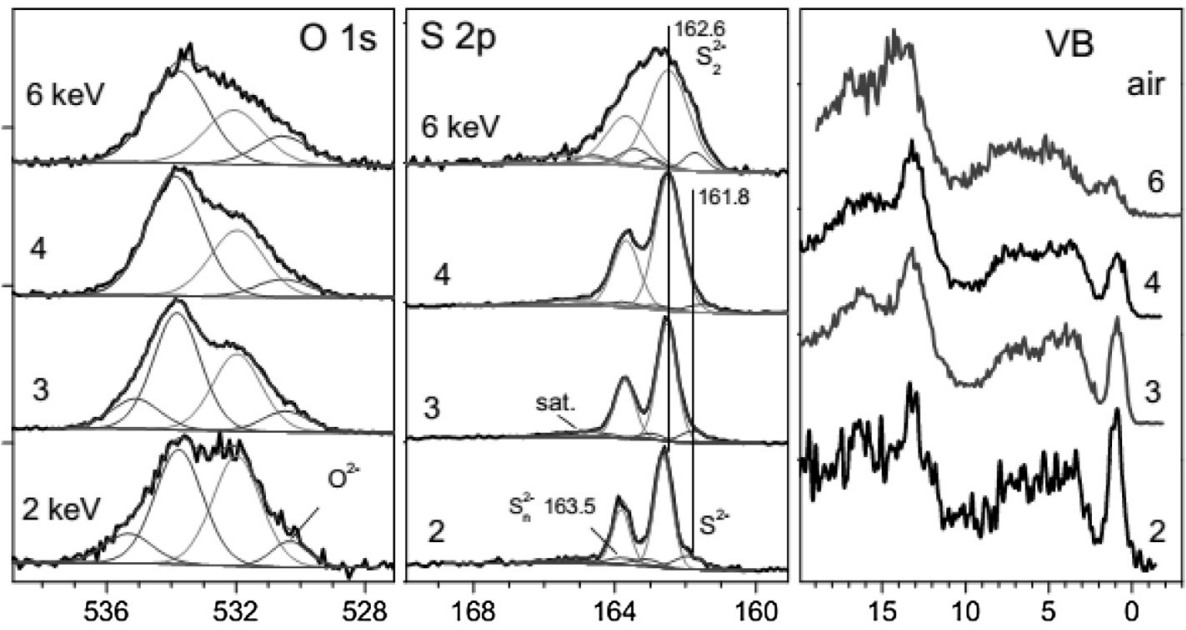

Binding energy (eV)

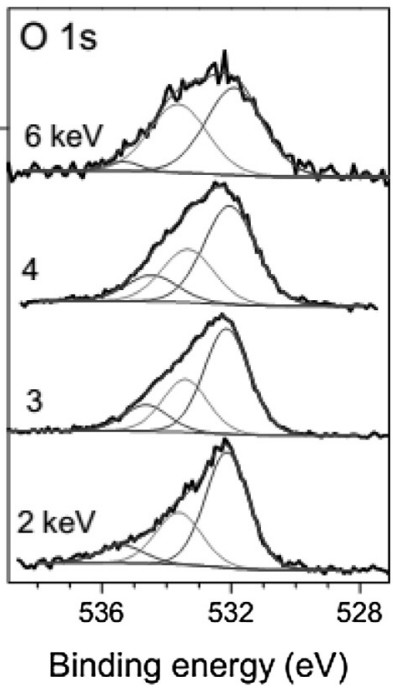

Binding energy (eV)

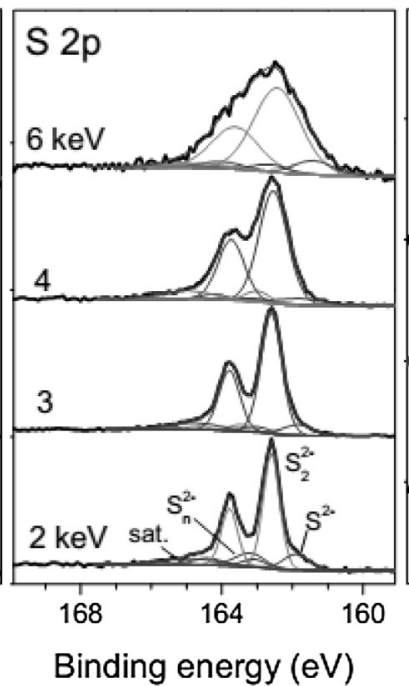

Binding energy (eV)

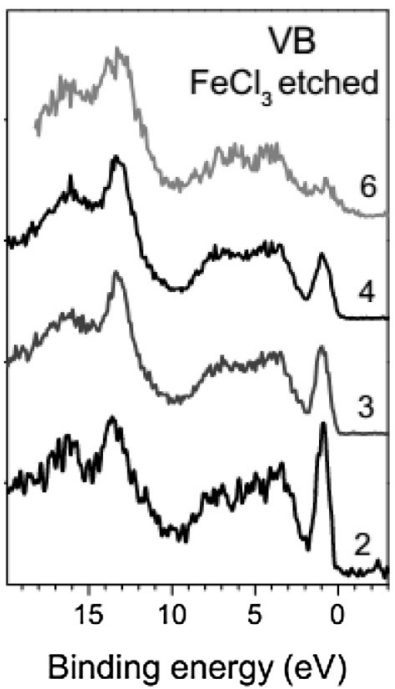

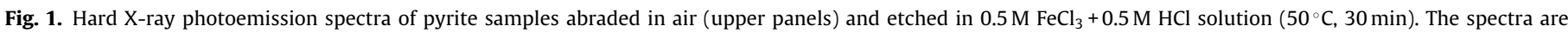
height-normalized for comparison; figures near the spectra indicate the employed excitation energies (in keV).

fide species signal in the $S 2 p$ spectra slightly increases, while that of monosulfide decreases.

Intensity ratios are presented as a function of excitation energy in Fig. 2, after accounting for differences in photoionization cross section, IMFP and transmission function of the electron analyzer. The results of the $S 2 \mathrm{p}$ and Fe $2 \mathrm{p}$ band fitting are also presented as a function of excitation photon energy in Fig. 2, with approximate information depths [37-42]. Whereas the calculated O/S and C/S ratios rapidly fall with increasing photon energy, the Fe/S ratios are higher at an excitation energy of $2 \mathrm{keV}$ but decrease to an approximately stoichiometric value of 0.5 (at $3 \mathrm{keV}$ ), at which it remains at higher excitation energies. The plots demonstrate that the concentrations of oxygen, carbon and, to a lower extent, iron at the etched sample decreases relative to air oxidized pyrite. Although the deviations from $\mathrm{FeS}_{2}$ stoichiometry are small, those are in agreement with enhanced amounts of polysulfide and reduced proportions of disulfide species. It should be mentioned that "disulfide" components with BE values ca. $162.5 \mathrm{eV}$ can be attributed to terminal S atoms in $\mathrm{S}_{\mathrm{n}}{ }^{2-}(n \geq 2)$ chains, while "polysulfide" components having $\mathrm{BE}$ values between $163 \mathrm{eV}$ and $164 \mathrm{eV}$ may be inner $\mathrm{S}$ atoms bearing lesser negative charge in the $S_{n}{ }^{2-}$ anions [34,59]. The intensities of polysulfide and monosulfide components decrease with increasing excitation energy; some increase of the monosulfide signal at $6 \mathrm{keV}$ seems to be an artifact of the line broadening.

\subsubsection{Pyrrhotite}

Fig. 3 (upper panels) shows the Fe 2p spectra of the in-air abraded pyrrhotite sample. The spectra can be fitted using a threepeak multiplet centered at a $\mathrm{BE}$ ca. $708 \mathrm{eV}$, ascribed to high-spin $\mathrm{Fe}(\mathrm{II})$ bonded to $\mathrm{S}$ in ferrous sulfide $[21,22]$. A second Fe $2 \mathrm{p}_{3 / 2}$ multiplet is also present at a $\mathrm{BE}$ around $710 \mathrm{eV}$, which is in line with $\mathrm{Fe}(\mathrm{III})-\mathrm{O}$ species; this second signal becomes weaker as the excitation energy increases from $2 \mathrm{keV}$ to $3 \mathrm{keV}$ and it slightly decreases at higher energies. The $\mathrm{O} 1 \mathrm{~s}$ spectra reveal intense maxima at a $\mathrm{BE}$ of $529.9 \mathrm{eV}$, ascribed to $\mathrm{O}^{2-}$ in ferric oxyhydroxides. The relative intensity of this oxygen state contribution insignificantly varies with increasing photon energy, while the total concentration of oxygen diminishes, as can be seen in Fig. 4. This observation suggests that the oxidized ferric species (oxyhydroxides) occur at the surface as islands or particles with $\mathrm{OH}^{-}$mainly at the outer shell and $\mathrm{O}^{2-}$ in the core. Regarding the $\mathrm{S} 2 \mathrm{p}$ spectra, the line of monosulfide $(161.3 \mathrm{eV})$ is dominant, and the contributions of disulfide and especially polysulfide are minor and generally decrease at higher excitation energies. 

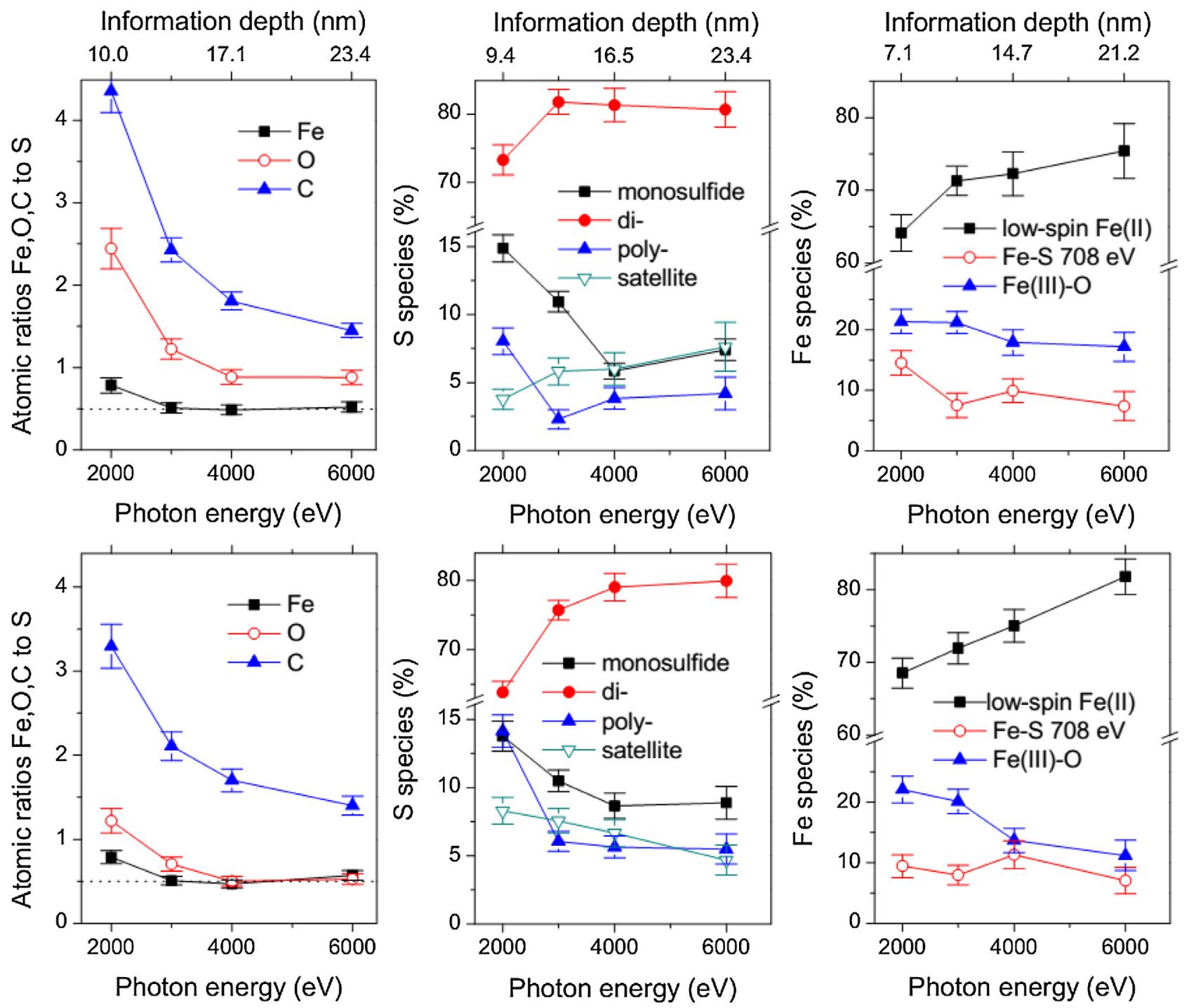

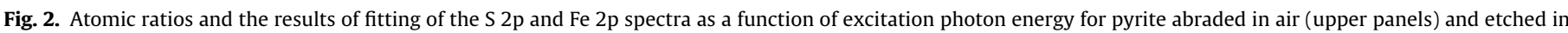
$0.5 \mathrm{M} \mathrm{FeCl}_{3}+0.5 \mathrm{M} \mathrm{HCl}$ solution.

The spectra of the sample treated in $0.5 \mathrm{M} \mathrm{FeCl}_{3}+0.5 \mathrm{M} \mathrm{HCl}$ are completely different (lower panels in Fig. 3). A narrow Fe $2 \mathrm{p}_{3 / 2}$ peak at $707.3 \mathrm{eV}$, which is attributable to low-spin $\mathrm{Fe}(\mathrm{II})$ in the S-rich layer [33-36], emerges along with a smaller feature conventionally approximated by one maximum located at $\sim 708.5 \mathrm{eV}$ from high-spin $\mathrm{Fe}(\mathrm{II})-\mathrm{S}$ and possible Fe(III)-S species. Small changes of these contributions with varying photon excitation energies (when taking into account spectral resolution issues discussed above and some growth of a high-spin Fe(II)-S component) suggest that the state of iron remains nearly constant for profile depths down to $\sim 30 \mathrm{~nm}$. The $S 2 \mathrm{p}$ spectra show that a doublet, which is ascribed to polysulfide ( $163.5 \mathrm{eV}$ ), is very strong in the $2 \mathrm{keV}$ excited spectrum and that decreases with higher excitation energies (Fig. 4, lower panel). In contrast, the mono- and disulfide contributions increase in measurements with greater information depths but are still significantly lower when compared to the results of the air-oxidized pyrrhotite. There are also very minor signals from S$\mathrm{O}$ species at the BEs above $166 \mathrm{eV}$. The atomic Fe/S ratio for this sample is high (about 1.3) at $2 \mathrm{keV}$, owing to the surface ferric oxyhydroxides, and approaches the stoichiometric ratio $(\sim 0.85)$ at $3 \mathrm{keV}$ and higher photon energies. For the etched mineral, the $\mathrm{Fe} / \mathrm{S}$ ratios are as low as 0.38 at $2 \mathrm{keV}$ and 0.3 at $3 \mathrm{keV}$, and exceed 0.5 at higher energies, remaining well below the stoichiometric value. The $\mathrm{O} / \mathrm{S}$ ratios slowly decrease with higher excitation energies but remain significantly high for all employed excitation energies. The $\mathrm{O} 1 \mathrm{~s}$ spectra retain some $\mathrm{O}^{2-}$ signals even in the $6 \mathrm{keV}$-excited spectra, which most likely indicates that oxygen penetrates deep into the metal-deficient structure during the chemical treatment or following exposure to the atmosphere. Similar findings have been reported in Auger profiling (and other techniques) studies of acid-reacted pyrrhotites [30-32]. In the valence band spectra, peaks located at BEs in the range of $12-16 \mathrm{eV}$ are derived from $\mathrm{S} 3 \mathrm{~s}$ type states, resembling molecular orbitals of $\mathrm{S}_{2}{ }^{2-}$ groups of pyrite, and indicate $S-S$ bonding. The Fe $3 \mathrm{~d}$ state peaks near the VB maximum appear weak and are probably widened and shifted as compared to pyrite.

\subsection{XANES}

Fig. 5 shows S K- and Fe K-edge XANES measured simultaneously in TEY and PFY modes from pyrites oxidized in air and etched in the $\mathrm{FeCl}_{3}$ solution. The leading peak $a$ in the $\mathrm{S}$ K-XANES results from transitions from the $S 1 \mathrm{~s}$ to the antibonding $S 3 p$ states in $\mathrm{S}_{2}{ }^{2-}$ anions; a shoulder $b$ together with a small pre-edge peak $b$ in 


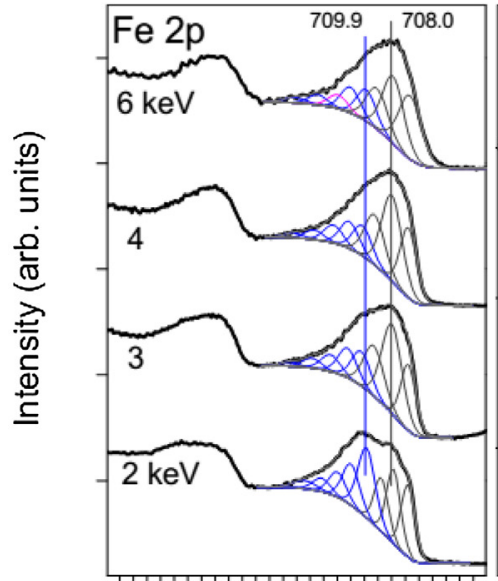

$\begin{array}{lllll}725 & 720 & 715 \quad 710 \quad 705\end{array}$

Binding energy (eV)

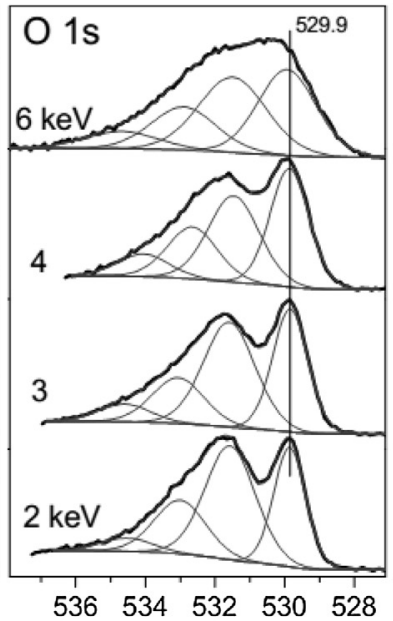

Binding energy (eV)
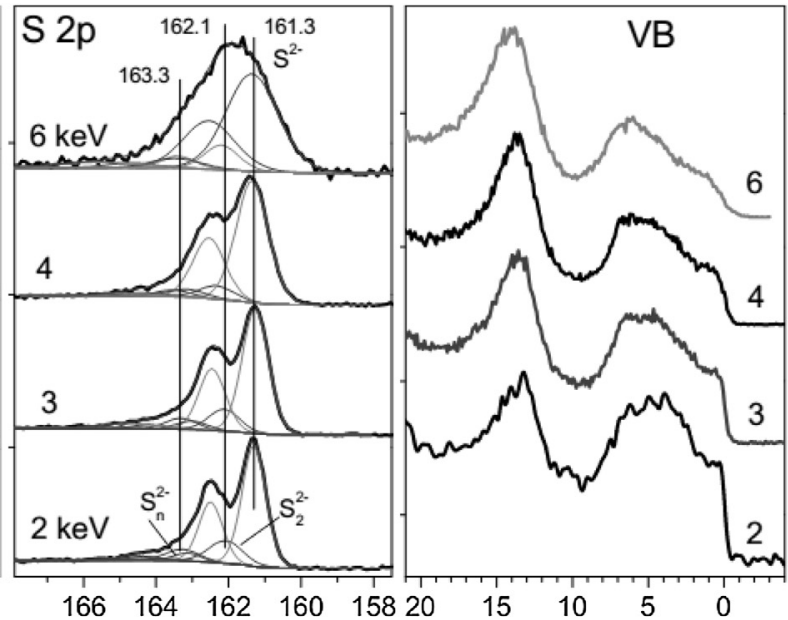

Binding energy $(\mathrm{eV})$

Binding energy (eV)

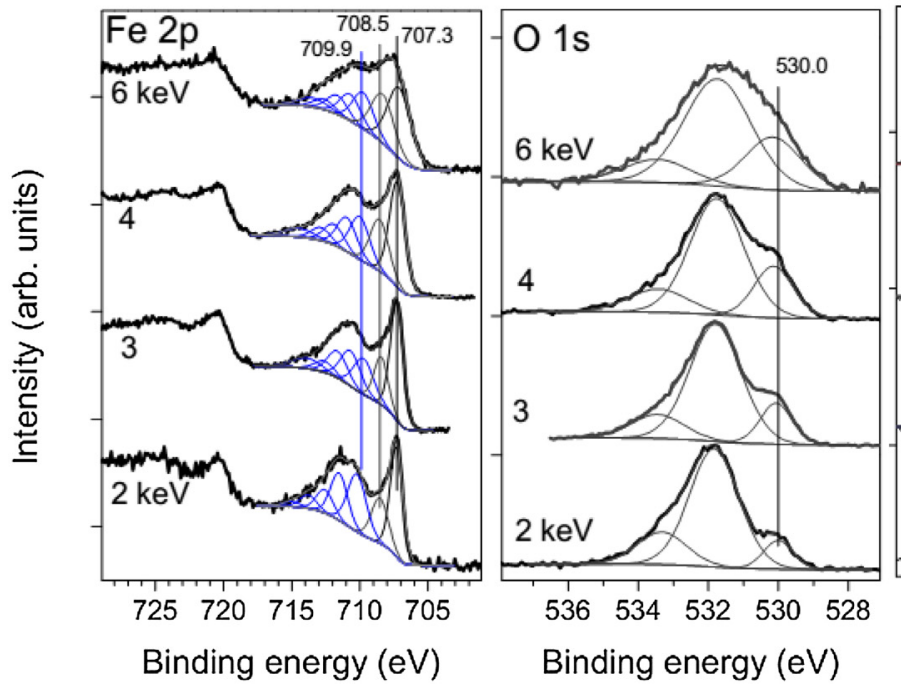

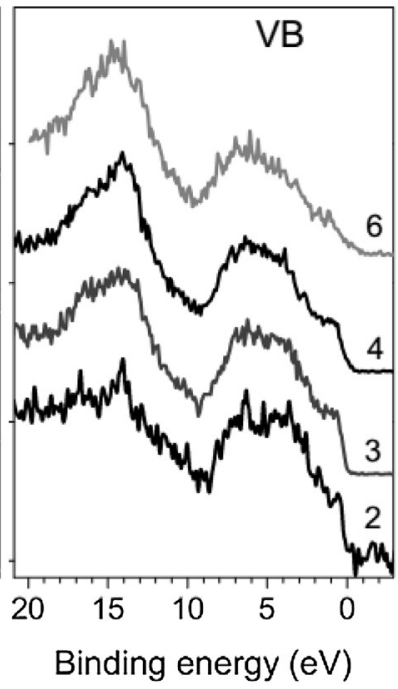

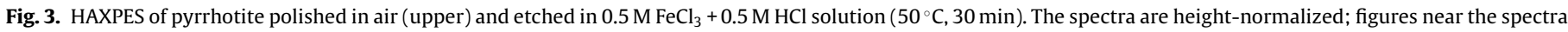
indicate the employed excitation energy (in keV).

the Fe K-edge spectra are commonly attributed to electron transitions from the core Fe $1 \mathrm{~s}$ to vacant Fe $3 \mathrm{~d}$ eg states mixed with Fe $4 \mathrm{p}$ and with $\mathrm{S} 3 \mathrm{p} \sigma^{*}$ states ( $1 \mathrm{~s}-3 \mathrm{~d}$ transitions are forbidden by dipole selection rules) [43-48]. The resonances $c$ correspond to Fe 4p,s states mixed with $\mathrm{S} 3 \mathrm{p} \sigma^{*}$ orbitals; the peak $d$ is due to transition to Fe $4 p, s$ states [43-48], and the feature $e$ can be assigned to transitions to atomic $S 3 p$ orbitals and multiple scattering resonances [45] or Fe 4sp-S 3d states [60]. The Fe K-edge XANES measured in the PFY mode do not change as a result of oxidation and etching and correspond to the bulk pyrite. In TEY mode spectra, the resonances $b$ are lower for air-oxidized sample and almost disappear after the oxidative leaching; the relative intensities of the shoulder $c$ are also smaller than for the bulk. The TEY mode S K-edge spectra revealed clearly different pre-edge peaks which are several times more intense relative to the absorption jump and narrower than in the PFY mode.

The XAS spectra of NiAs-structured pyrrhotite and stoichiometric troilite FeS have been measured, calculated and analyzed in a number of studies; the spectroscopic features are largely similar to those in pyrite, despite different electronic structures, and their detailed description can be found in the literature [43-56]. The main differences observed in the S K-edge XANES (Fig. 6) are narrower pre-edge peaks with lower heights relative to the absorption edge, which are attributable to the absence of $\mathrm{S}-\mathrm{S}$ bonding
[47]. Similar to pyrite, both the S K-edge and Fe K-edge spectra collected in PFY mode did not change significantly after sample oxidation, indicating that the modified region is shorter than the probing depth of the technique. The pre-edge maxima of the Fe KXANES of pyrrhotite almost disappeared in the spectra measured in TEY mode. Additional intensity shifted by $2-2.5 \mathrm{eV}$ to higher energy relative to the main pre-edge peak arose in the $S$ K-XANES TEY spectra that can be assigned to S-S bonding in the metal-deficient structure, as its position is close to that in pyrite.

\section{Discussion}

Omitting water-derived adsorbates and carbon contamination, the HAXPES data suggests the presence of surface ferric oxyhydroxides at pyrite and pyrrhotite, probably as islands of several $\mathrm{nm}$ in height (Fig. 7). Additionally, the near-surface region of pyrite exhibits enhanced contents of $S$, polysulfide-type species and some monosulfide ions as compared to the $\mathrm{FeS}_{2}$ composition. The thickness of this region is significantly lower than the measurement information depths of $10-15 \mathrm{~nm}$ [37,38], estimated at $1-2 \mathrm{~nm}$ for air-exposed pyrite and no greater than $3-4 \mathrm{~nm}$ for the ferric chloride etched mineral. Furthermore, there likely exists an extended region with insignificant compositional changes ("Fedepleted layer") beneath the "polysulfide" layer, at least, in the 


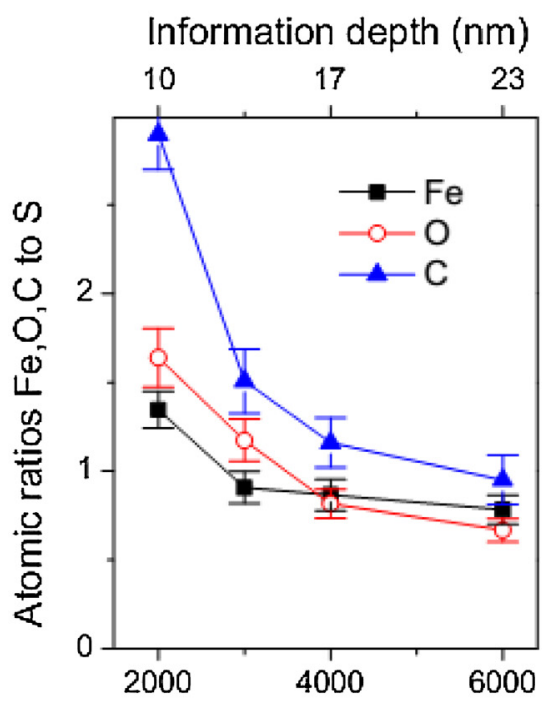

Photon energy (eV)

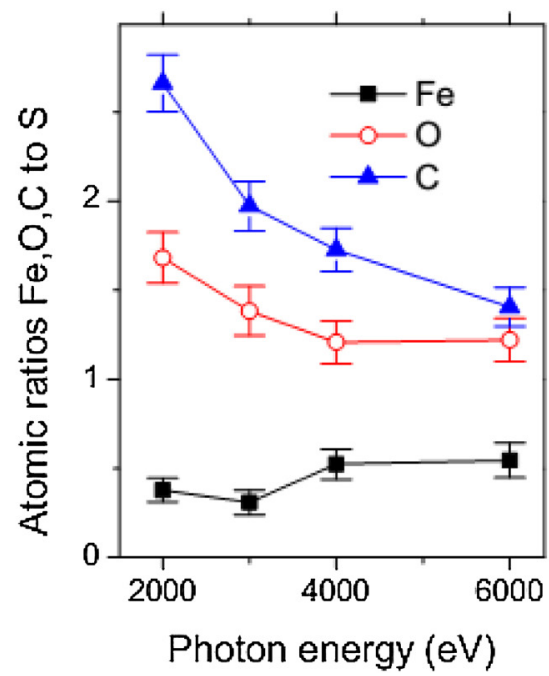

Information depth (nm)

$\begin{array}{lll}9.4 & 16.5 & 23.4\end{array}$

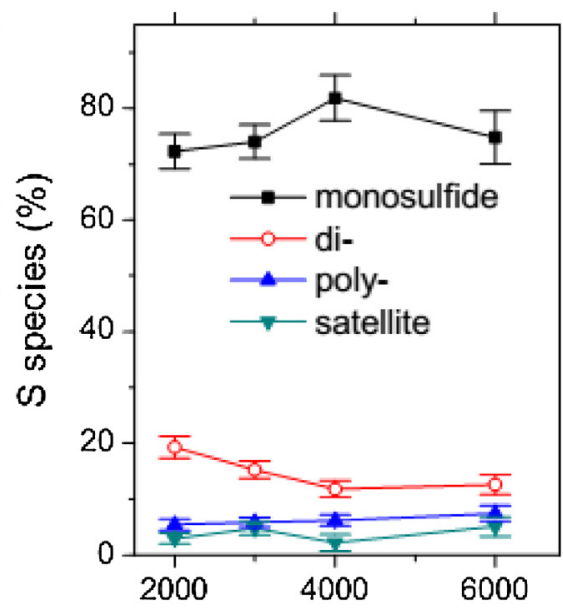

Photon energy (eV)

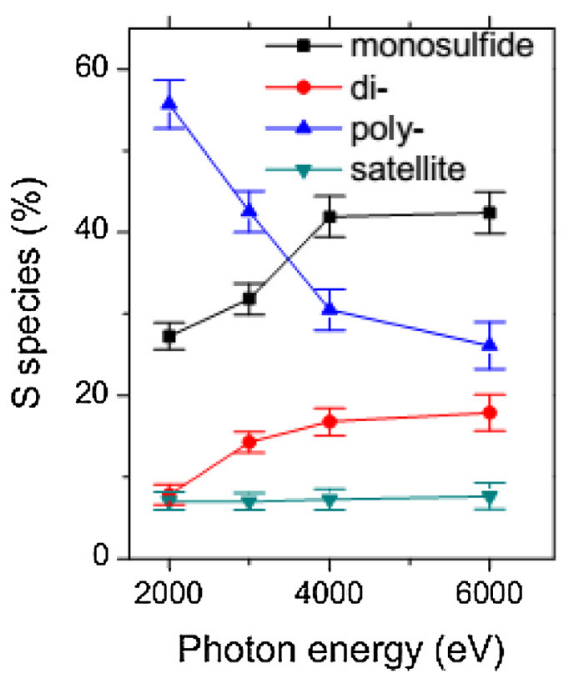

Information depth (nm)

7.1

14.7

21.2

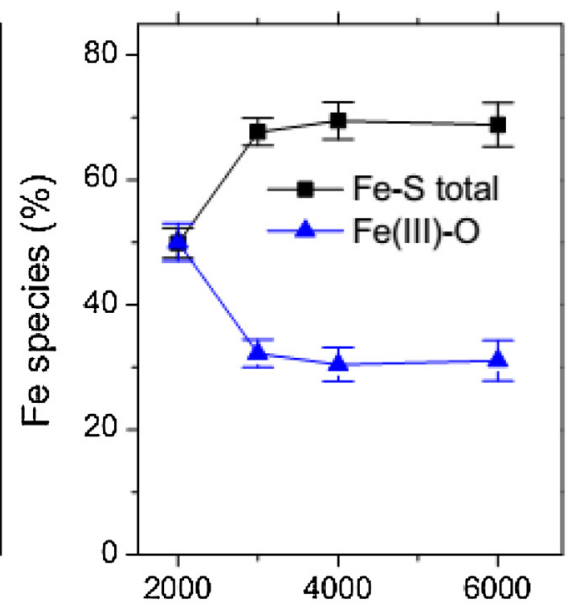

Photon energy (eV)

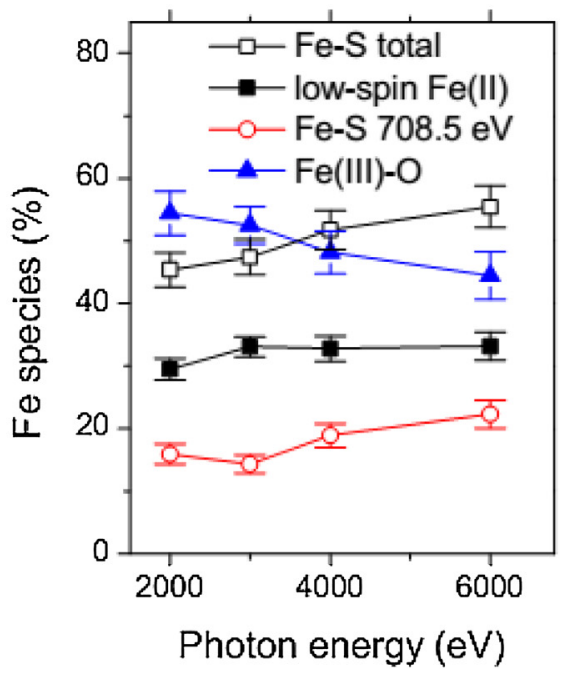

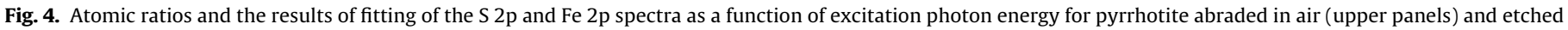
in $0.5 \mathrm{M} \mathrm{FeCl}_{3}+0.5 \mathrm{M} \mathrm{HCl}$ solution (lower panels).

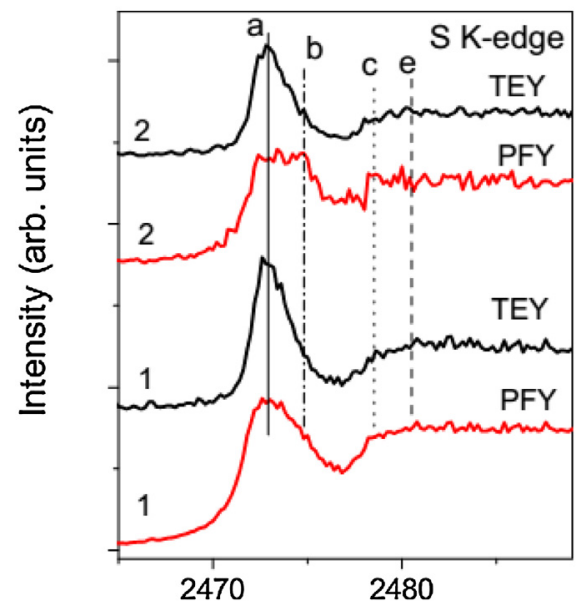

Photon energy (eV)

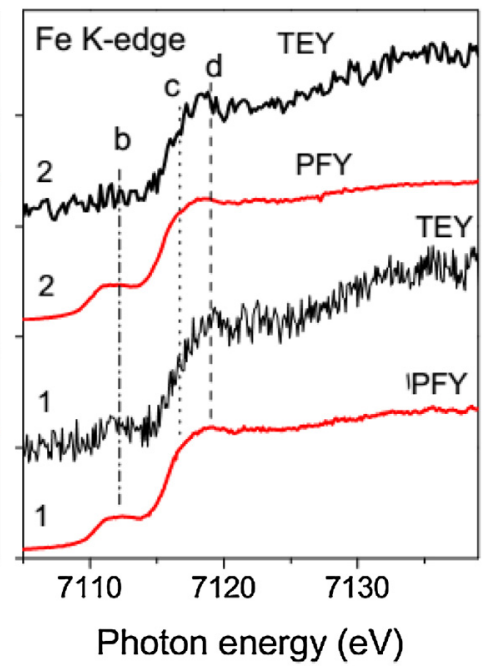

Fig. 5. S K-edge and Fe K-edge XANES from pyrite (1) abraded in air and (2) etched in $0.5 \mathrm{M} \mathrm{FeCl}_{3}+0.5 \mathrm{M} \mathrm{HCl}$ solution $\left(30\right.$ min, $\left.50{ }^{\circ} \mathrm{C}\right)$ collected in TEY and $\mathrm{PFY}$ modes. 


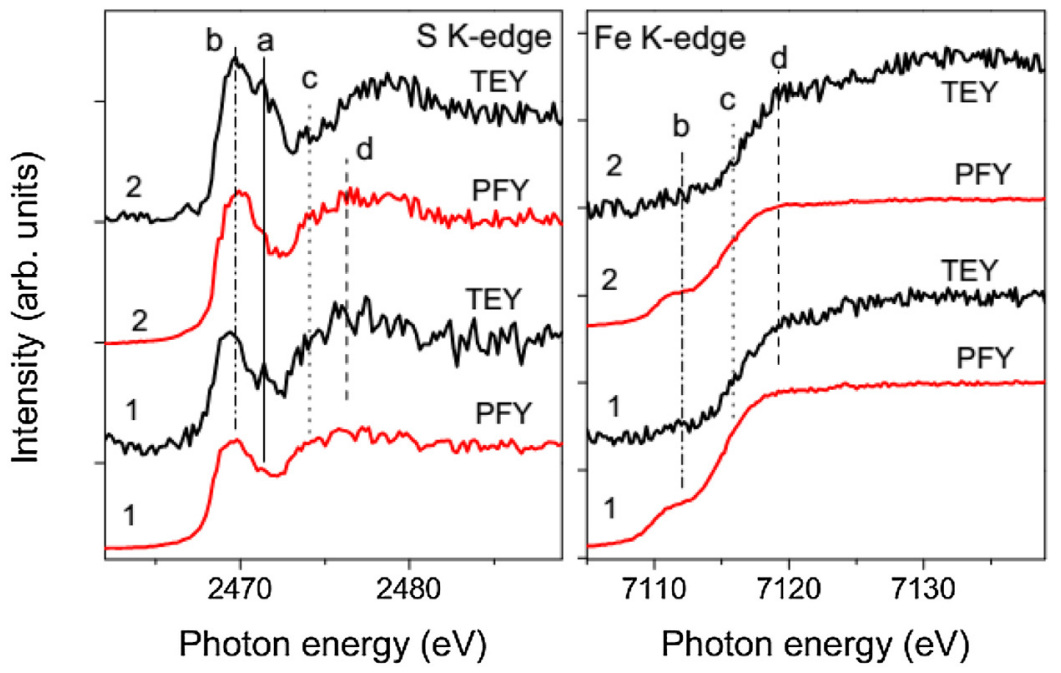

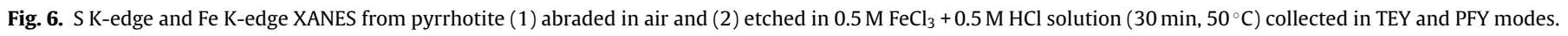
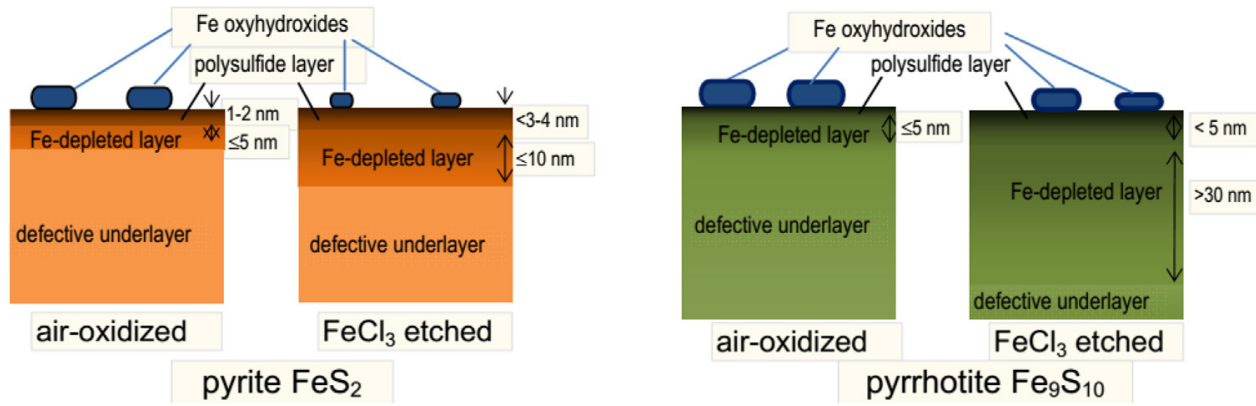

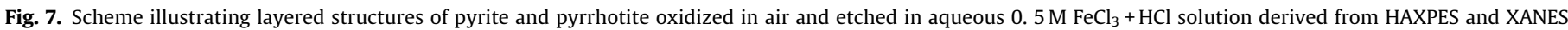
spectra.

etched sample. It should be noted that attempts to more precisely calculate the thicknesses involved were limited due to multilayered and laterally inhomogeneous compositions and complex relief of the studied mineral surfaces.

The HAXPES analysis of air-oxidized pyrrhotite revealed, underneath ferric oxyhydroxide species, the iron-deficient layer (Fig. 7), probably $1-5 \mathrm{~nm}$ thick, containing $20-25 \%$ of sulfur as disulfide and minor polysulfide species. After the oxidative etching, the amount of oxyhydroxides decreases, and a metal-deficient region composed of an essentially S-rich layer with polysulfide species forms, the thickness of which may be roughly estimated as less than $5 \mathrm{~nm}$. Finally, the underlying layer of at least $30 \mathrm{~nm}$ in depth has an atomic $\mathrm{S} / \mathrm{Fe}$ ratio of approximately 2 and also contains mono- and disulfide anions, Fe(II) in low-spin and high-spin state and, possibly, Fe(III), and some oxygen.

The information depths of the XANES spectra in TEY mode controlled by the penetration ranges of Auger electrons with the largest kinetic energies emitted from the absorbing atoms [61,62] are somewhat larger but still comparable to those of HAXPES at the higher excitation photon energies, while the spectra in PFY mode characterize, in fact, the bulk of the materials. The XANES data (Figs. 5 and 6) show that the oxidative etching and even air oxidation moderately modify the near-surface composition of iron sulfides, in particular refractory pyrite, altering the electronic structure of the materials at depths of many tens of nanometers (Fig. 7).

The structures observed are definitely due to preferential release of iron and the formation of heavily defective metal-deficient layers comprising cation vacancies and complexes of defects, S-S bonding and possibly oxygen incorporation. This should modify the elec- tronic properties of semiconducting metal chalcogenides, including the Fermi level pinning, carrier mobility and conductivity. Up to now, researchers have largely focused their attention on outer surface layers, while the underlying extended defective region could seriously affect surface processes in which the charge transport is important. We hypothesize, in particular, that such structures should take part in the inhibited anodic oxidation and oxidative leaching of pyrite, pyrrhotite and other metal sulfides [1-4,63-66]. Noteworthy, the above phenomena arise as a result of the sample handling in atmosphere, that is, in the early stages of metal sulfide oxidation. Further work should be focused on studying detailed characteristics of the reacted layers in order to understand their role.

\section{Conclusions}

HAXPES and XANES characterization of pyrite and pyrrhotite revealed that the composition and chemical state of iron and sulfur varied with depth from the surface to at least several tens of nanometers as a result of oxidation of the minerals in air and the oxidative etching in $\mathrm{Fe}(\mathrm{III})$ solution. Iron is released from the metal sulfide lattice, creating strongly modified regions at pyrrhotite, whereas the compositional changes at pyrite are less pronounced. In addition to surface ferric oxyhydroxides formed at the surfaces exposed to air, several sublayers may be distinguished in the under-surface regions of the reacted iron sulfide phases. Polysulfide species are accumulated only in thin, no more than $1-4 \mathrm{~nm}$ in depth, outer layers. The region with smaller deviations from the stoichiometry and low, if any, concentration of polysulfide lays 
underneath; its dimensions widely vary for pyrite and pyrrhotite depending on the chemical treatment. In pyrrhotite samples etched in ferric chloride solution, this layer with about $30 \mathrm{~nm}$ or more thickness comprises mono- and disulfide anions, and low-spin $\mathrm{Fe}(\mathrm{II})$. The next, almost stoichiometric layers exhibit altered the XANES spectra in TEY mode, implying spatially extended distortion of the crystalline structures, even for chemically resistive pyrite, already after oxidation in air. We suggest that these highly defective regions are the most important in terms of the pinning of the Fermi level and near-surface charge transfer, in particular, in mineral passivation, and require further investigation.

\section{Acknowledgements}

This research was supported by the Russian Science Foundation, grant 14-17-00280, and bilateral program "German-Russian laboratory at BESSY II". We thank HZB for the allocation of synchrotron radiation beamtime for HAXPES/XANES measurements.

\section{References}

[1] D. Rickard, G.W. Luther III, Chemistry of iron sulfides, Chem. Rev. 107 (2007) 514-562.

[2] J.D. Rimstidt, D.J. Vaughan, Pyrite oxidation: a state of-the-art-assessment of the reaction mechanism, Geochim. Cosmochim. Acta 67 (2003) 873-880.

[3] R. Murphy, D.R. Strongin, Surface reactivity of pyrite and related sulfides, Surf. Sci. Rep. 64 (2009) 1-45

[4] A.P. Chandra, A.R. Gerson, The mechanisms of pyrite oxidation and leaching: a fundamental perspective, Surf. Sci. Rep. 65 (2010) 293-315.

[5] K. Andersson, M. Nyberg, H. Ogasawara, D. Nordlund, T. Kendelewicz, C.S. Doyle, G.E. Brown Jr., L.G.M. Pettersson, A. Nilsson, Experimental and theoretical characterization of the structure of defects at the pyrite $\mathrm{FeS}_{2}$ (100) surface, Phys. Rev. B 70 (2004) 195404.

[6] F.W. Herbert, A. Krishnamoorthy, K.J. Van Vliet, B. Yildiz, Quantification of electronic band gap and surface states on $\mathrm{FeS}_{2}$ (100), Surf. Sci. 618 (2013) 53-61, http://dx.doi.org/10.1016/j.susc.2013.08.014.

[7] P. Xiao, X.L. Fan, L.-M. Liu, W.-M. Lau, Band gap engineering of $\mathrm{FeS}_{2}$ under biaxial strain: a first principles study, Phys. Chem. Chem. Phys. 16 (2014) 24466-24472

[8] A. Ennaoui, S. Fiechter, Ch. Pettenkofer, N. Alonso-Vante, K. Bülker, M. Bronold, Ch. Höpfner, H. Tributsch, Iron disulfide for solar energy conversion, Sol. Energy Mater. Sol. Cells 29 (1993) 289-370.

[9] C. Steinhagen, T.B. Harvey, C.J. Stolle, J. Harris, B.A. Korgel, Pyrite nanocrystal solar cells: promising or fool's gold? J. Phys. Chem. Lett. 3 (2012) 2352-2356.

[10] D. Golodnitsky, E. Peled, Pyrite as cathode insertion material in rechargeable lithium/composite polymer electrolyte batteries, Electrochim. Acta 45 (1999) $335-350$.

[11] S.S. Zhang, The redox mechanism of $\mathrm{FeS}_{2}$ in non-aqueous electrolytes for lithium and sodium batteries, J. Mater. Chem. A 3 (2015) 7689-7694.

[12] C. Uhlig, E. Guenes, A.S. Schulze, M.T. Elm, P.J. Klar, S. Schlecht, Nanoscale FeS (pyrite) as a sustainable thermoelectric material, J. Electron. Mater. 43 (2014) 2362-2370.

[13] E.F. Bertaut, Contribution à l'étude des structures lacunaires, Acta Crystallogr. 6 (1953) 537-561

[14] S. Sakkopoulos, E. Vitoratos, T. Argyreas, Energy-band diagram for pyrrhotite J. Phys. Chem. Solids 45 (1984) 923-928.

[15] A.N. Buckley, R. Woods, X-ray photoelectron spectroscopy of oxidized pyrrhotite surfaces I. Exposure to air, Appl. Surf. Sci. 22/23 (1985) 280-287.

[16] A.N. Buckley, R. Woods, X-ray photoelectron spectroscopy of oxidized pyrrhotite surfaces. II: exposure to aqueous solutions, Appl. Surf. Sci. 20 (1985) 472-480.

[17] J.R. Mycroft, G.M. Bancroft, N.S. McIntyre, J.W. Lorimer, I.R. Hill, Detection of sulfur and polysulfides on electrochemically oxidized pyrite surfaces by X-ray photoelectron-spectroscopy and Raman-spectroscopy, J. Electroanal. Chem. 292 (1990) 139-152.

[18] H.W. Nesbitt, I.J. Muir, X-ray photoelectron spectroscopic study of a pristine pyrite surface reacted with water-vapor and air, Geochim. Cosmochim. Acta 58 (1994) 4667-4679.

[19] C.M. Eggleston, J.J. Ehrhardt, W. Stumm, Surface structural controls on pyrite oxidation kinetics: an XPS-UPS, STM, and modeling study, Am. Mineral. 81 (1996) 1036-1056.

[20] A.G. Schaufuss, H.W. Nesbitt, I. Kartio, K. Laajalehto, G.M. Bancroft, R. Szargan, Reactivity of surface chemical states on fractured pyrite, Surf. Sci. 411 (1998) 321-328.

[21] H.W. Nesbitt, G.M. Bancroft, A.R. Pratt, M.J. Scaini, Sulfur and iron surface states on fractured pyrite surfaces, Am. Mineral. 83 (1998) 1067-1076.

[22] H.W. Nesbitt, M. Scaini, H. Hochst, G.M. Bancroft, A.G. Schaufuss, R. Szargan, Synchrotron XPS evidence for $\mathrm{Fe}^{2+}-\mathrm{S}$ and $\mathrm{Fe}^{3+}-\mathrm{S}$ surface species on pyrite fracture-surfaces, and their 3d electronic states, Am. Mineral. 85 (2000) $850-857$.

[23] J.A. Leiro, S.S. Mattila, K. Laajalehto, XPS study of the sulphur 2p spectra of pyrite, Surf. Sci. 547 (2003) 157-161.

[24] G.U. von Oertzen, W.M. Skinner, H.W. Nesbitt, Ab initio and X-ray photoemission spectroscopy study of the bulk and surface electronic structure of pyrite (100) with implications for reactivity, Phys. Rev. B 72 (2005) 235427

[25] A.P. Chandra, A.R. Gerson, Pyrite $\left(\mathrm{FeS}_{2}\right)$ oxidation: a sub-micron synchrotron investigation of the initial steps, Geochim. Cosmochim. Acta 75 (2011) 6239-6254.

[26] F.W. Herbert, A. Krishnamoorthy, W. Ma, K.J. Van Vliet, B. Yildiz, Dynamics of point defect formation, clustering and pit initiation on the pyrite surface, Electrochim. Acta 127 (2014) 416-426.

[27] C.F. Jones, S. LeCount, R.St.C. Smart, T.J. White, Compositional and structural alteration of pyrrhotite surfaces in solution: XPS and XRD studies, Appl. Surf. Sci. 55 (1992) 65-85.

[28] J.E. Thomas, C.F. Jones, W.M. Skinner, R.St.C. Smart, The role of surface sulfur species in the inhibition of pyrrhotite dissolution in acid conditions, Geochim. Cosmochim. Acta 62 (1998) 1555-1565.

[29] A.R. Pratt, I.J. Muir, H.W. Nesbitt, X-ray photoelectron and Auger electron studies of pyrrhotite and mechanism of air oxidation, Geochim. Cosmochim. Acta 58 (1994) 827-841.

[30] A.R. Pratt, H.W. Nesbitt, I.J. Muir, Generation of acids from mine waste: oxidative leaching of pyrrhotite in dilute $\mathrm{H}_{2} \mathrm{SO}_{4}$ solutions ( $\mathrm{pH} 3$ ), Geochim. Cosmochim. Acta 58 (1994) 5147-5159.

[31] A.R. Pratt, H.W. Nesbitt, Pyrrhotite leaching in acid mixtures of $\mathrm{HCl}$ and $\mathrm{H}_{2} \mathrm{SO}_{4}$, Am. J. Sci. 297 (1997) 807-820.

[32] J.R. Mycroft, H.W. Nesbitt, A.R. Pratt, X-ray photoelectron and Auger electron spectroscopy of air-oxidized pyrrhotite: distribution of oxidized species with depth, Geochim. Cosmochim. Acta 59 (1995) 721-733.

[33] Yu.L. Mikhlin, Ye.V. Tomashevich, G.L. Pashkov, A.V. Okotrub, I.P. Asanov, L.N. Mazalov, Electronic structure of the non-equilibrium iron-deficient layer of hexagonal pyrrhotite, Appl. Surf. Sci. 125 (1998) 73-84.

[34] Yu. Mikhlin, V. Varnek, I. Asanov, Ye. Tomashevich, A. Okotrub, A. Livshits, G. Selyutin, G. Pashkov, Reactivity of pyrrhotite $\left(\mathrm{Fe}_{9} \mathrm{~S}_{10}\right)$ surfaces: spectroscopic studies, Phys. Chem. Chem. Phys. 2 (2000) 4393-4398

[35] Yu.L. Mikhlin, A.V. Kuklinskiy, N.I. Pavlenko, V.A. Varnek, I.P. Asanov, A.V. Okotrub, G.E. Selyutin, L.A. Solovyev, Spectroscopic and XRD studies of the air degradation of acid-reacted pyrrhotites, Geochim. Cosmochim. Acta 66 (2002) 4077-4087

[36] Yu. Mikhlin, Ye. Tomashevich, Pristine and reacted surfaces of pyrrhotite and arsenopyrite as studied by X-ray absorption near-edge structure spectroscopy, Phys. Chem. Minerals 32 (2005) 19-27.

[37] C.J. Powell, A. Jablonski, Surface sensitivity of X-ray photoelectron spectroscopy, Nucl. Instrum. Methods A 601 (2009) 54-65.

[38] S. Tanuma, H. Yoshikawa, H. Shinotsuka, R. Ueda, Calculations of mean escape depths of photoelectrons in elemental solids excited by linearly polarized $\mathrm{X}$-rays for high-energy photoelectron spectroscopy, J. Electron Spectrosc. Relat. Phenom. 190 (Part B) (2013) 127-136, http://dx.doi.org/10.1016/j. elspec.2013.08.011.

[39] M. Gorgoi, S. Svensson, F. Schäfers, G. Öhrwall, M. Mertin, P. Bressler, O. Karis, H. Siegbahn, A. Sandell, H. Rensmo, W. Doherty, C. Jung, W. Braun, W. Eberhardt, The high kinetic energy photoelectron spectroscopy facility at BESSY progress and first results, Nucl. Instrum. Methods A 601 (2009) 48-53, http://dx.doi.org/10.1016/j.nima.2008.12.244.

[40] M. Gorgoi, N. Mårtensson, S. Svensson, HAXPES studies of solid materials for applications in energy and information technology using the HIKE facility at HZB-BESSY II, J. Electron Spectrosc. Relat. Phenom. 200 (2015) 40-48.

[41] H. Mönig, Ch.-H. Fischer, R. Caballero, C.A. Kaufmann, N. Allsop, M. Gorgoi, R. Klenk, H.-W. Schock, S. Lehmann, M.C. Lux-Steiner, I. Lauermann, Surface Cu depletion of $\mathrm{Cu}(\mathrm{In}, \mathrm{Ga}) \mathrm{Se}_{2}$ films: an investigation by hard X-ray photoelectron spectroscopy, Acta Mater. 57 (2009) 3645-3651, http://dx.doi.org/10.1016/j. actamat.2009.04.029.

[42] B. Ümsür, W. Calvet, B. Höpfner, A. Steigert, I. Lauermann, M. Gorgoi, K. Prietzel, H.A. Navirian, C.A. Kaufmann, T. Unold, M.Ch. Lux-Steiner, Investigation of $\mathrm{Cu}$-poor and $\mathrm{Cu}$-rich $\mathrm{Cu}(\mathrm{In}, \mathrm{Ga}) \mathrm{Se}_{2} / \mathrm{CdS}$ interfaces using hard X-ray photoelectron spectroscopy, Thin Solid Films 582 (2015) 366-370.

[43] C. Sugiura, Sulfur K X-ray absorption spectra of $\mathrm{FeS}, \mathrm{FeS}_{2}$, and $\mathrm{Fe}_{2} \mathrm{~S}_{3}$, J. Chem. Phys. 74 (1981) 215-217

[44] C. Sugiura, Iron K X-ray absorption-edge structure of FeS and FeS2, J. Chem. Phys. 80 (1984) 1047-1049.

[45] J.F.W. Mosselmans, R.A.D. Pattrick, G. van der Laan, J.M. Charnock, D.J. Vaughan, C.M.B. Henderson, C.D. Garner, X-ray absorption near-edge spectra of transition metal disulfides (pyrite and marcasite), $\mathrm{CoS}_{2} \mathrm{NiS}_{2}$ and $\mathrm{CuS}_{2}$, and their isomorphs FeAsS and CoAsS, Phys. Chem. Minerals 22 (1995) 311-317.

[46] D. Li, G.M. Bancroft, M. Kasrai, M.E. Fleet, X. Feng, K. Tan, S K- and L-edge X-ray absorption spectroscopy of metal sulfides and sulfates: applications in mineralogy and geochemistry, Can. Mineral. 33 (1995) 949-960.

[47] M. Womes, R.C. Karnatak, J.M. Esteva, I. Lefebvre, G. Allan, J. Olivier-Fourcade, J.C. Jumas, Electronic structures of $\mathrm{FeS}$ and $\mathrm{FeS}_{2}$ : X-ray absorption spectroscopy and band structure calculations, J. Phys. Chem. Solids 58 (1997) $345-352$.

[48] K.E.R. England, J.M. Charnock, R.A.D. Pattrick, D.J. Vaughan, Surface oxidation studies of chalcopyrite and pyrite by glancing-angle X-ray absorption spectroscopy (REFLEXAFS), Mineral. Mag. 63 (1999) 559-566. 
[49] S.P. Farrell, M.E. Fleet, I.E. Stekhin, A. Kravtsova, A.V. Soldatov, X. Liu, Evolution of local electronic structure in alabandite and niningerite solid solutions [(Mn,Fe)S, (Mg,Mn)S, (Mg,Fe)S using sulfur $\mathrm{K}$ and L-edge XANES spectroscopy, Am. Mineral. 87 (2002) 1321-1332.

[50] P.A. O’Day, N. Rivera Jr., R. Root, S.A. Carroll, X-ray absorption spectroscopic study of Fe reference compounds for the analysis of natural sediments, Am. Mineral. 89 (2004) 572-585.

[51] L.A.J. Garvie, P.R. Buseck, Unoccupied states of pyrite probed by electron energy-loss spectroscopy (EELS), Am. Miner. 89 (2004) 485-491.

[52] A.N. Kravtsova, I.E. Stekhin, A.V. Soldatov, X. Liu, M.E. Fleet, Electronic structure of MS (M = Ca,Mg,Fe,Mn): X-ray absorption analysis, Phys. Rev. B 69 (2004) 134109

[53] A.V. Soldatov, A.N. Kravtsova, M.E. Fleet, S.L. Harmer, Electronic structure of $\mathrm{MeS}(\mathrm{Me}=\mathrm{Ni}, \mathrm{Co}, \mathrm{Fe})$ : X-ray absorption analysis, J. Phys. Condens. Matter 16 (2004) 7545-7556.

[54] M.E. Fleet, XANES spectroscopy of sulfur in Earth materials, Can. Mineral. 43 (2005) 1811-1838

[55] T. Oguchi, H. Momida, First-principles study of X-ray absorption spectra of $\mathrm{FeS}_{2}$, J. Phys. Soc. Jpn. 82 (2013) 065004

[56] A. Kitajou, J. Yamaguchi, S. Hara, S. Okada, Discharge/charge reaction mechanism of a pyrite-type $\mathrm{FeS}_{2}$ cathode for sodium secondary batteries, J. Power Sources 247 (2014) 391-395.

[57] M.B. Trzhaskovskaya, V.I. Nefedov, V.G. Yarzhemsky, Photoelectron angular distribution parameters for elements $\mathrm{Z}=1$ to $\mathrm{Z}=54$ in the photoelectron energy range 100-5000 eV, At. Data Nucl. Data Tables 77 (2001) 97-159.

[58] M.B. Trzhaskovskaya, V.I. Nefedov, V.G. Yarzhemsky, Photoelectron angular distribution parameters for elements $Z=55$ to $Z=100$ in the photoelectron energy range 100-5000 eV, At. Data Nucl. Data Tables 82 (2002) 257-311.
[59] A.N. Buckley, H.J. Wouterland, P.S. Cartwright, R.D. Gilbuckley, Core electron binding energies of platinium and rhodium polysulfides, Inorg. Chim. Acta 143 (1988) 77-80.

[60] T. Ollonqvist, R. Perälä, J. Väyrynen, Unoccupied electronic states of the FeS (100) surface studies by inverse photoemission, Surf. Sci. 377-379 (1997) 201-205.

[61] A. Erbil, G.S. Cargill III, R. Frahm, R.F. Boehme, Total-electron-yield current measurements for near-surface extended X-ray-absorption fine structure, Phys. Rev. B 37 (1988) 2450-2464.

[62] S.L.M. Schroeder, Towards a 'universal curve' for total electron-yield XAS, Solid State Commun. 98 (1996) 405-409.

[63] Y. Mikhlin, Y. Tomashevich, A. Kuklinskiy, D. Shipin, I. Asanov, A. Okotrub, V. Varnek, N. Bausk, Passivation of sulfide minerals: are the metal-deficient layers responsible?, In: Electrochemistry in mineral and metal processing VI, F.M. Doyle, G.H. Kelsall, R. Woods (Eds.), Electrochem. Soc. Proc. vol. 18, Pennington, NY, 2003, pp. 96-107.

[64] Yu. L. Mikhlin, Ye.V. Tomashevich, I.P. Asanov, A.V. Okotrub, V.A. Varnek, D.V. Vyalikh, Spectroscopic and electrochemical characterization of the surface layers of chalcopyrite $\left(\mathrm{CuFeS}_{2}\right)$ reacted in acidic solutions, Appl. Surf. Sci. 225 (2004) 395-409.

[65] P.R. Holmes, F.K. Crundwell, Polysulfides do not passivate: results from pyrite and implications for other sulfide minerals, Hydrometallurgy 139 (2013) 101-110, http://dx.doi.org/10.1016/j.hydromet.2013.07.006.

[66] R.H. Lara, J. Vazquez-Arenas, G. Ramos-Sanchez, M. Galvan, L. Lartundo-Rojas, Experimental and theoretical analysis accounting for differences of pyrite and chalcopyrite oxidative behaviors for prospective environmental and bioleaching applications, J. Phys. Chem. C 119 (2015) 18364-18379. 